\title{
Comparison of the behavioral effects of cigarette smoke and pure nicotine in rats
}

\author{
Andrew C. Harris ${ }^{a}$, Christina Mattson, Mark G. LeSage ${ }^{a}$, Daniel E. Keylera,b, and Paul R. \\ Pentela,c \\ Minneapolis Medical Research Foundation, Minneapolis, MN, Minneapolis, MN \\ a Department of Medicine, University of Minnesota Medical School \\ b Department of Experimental \& Clinical Pharmacology, College of Pharmacy, University of \\ Minnesota \\ ${ }^{c}$ Department of Pharmacology, University of Minnesota
}

\begin{abstract}
Animal models of tobacco dependence typically rely on parenteral administration of pure nicotine. Models using cigarette smoke inhalation might more accurately simulate nicotine exposure in smokers. The primary goal of this study was to validate methods for administering cigarette smoke to rats using exposure conditions that were clinically relevant and also produced brain nicotine levels similar to those produced by behaviorally active doses of pure nicotine. A secondary goal was to begin examining the behavioral effects of smoke. Nose-only exposure (NOE) to smoke for 10-45 min or whole-body exposure (WBE) to smoke for 1-4 hr produced serum nicotine concentrations similar to those in smokers $(14-55 \mathrm{ng} / \mathrm{ml})$, without excessive carbon monoxide exposure. Daily nicotine $(0.1 \mathrm{mg} / \mathrm{kg}$, s.c. $)$ induced locomotor sensitization whereas 45 -min NOE producing brain nicotine levels within the same range did not. Nicotine $0.125 \mathrm{mg} / \mathrm{kg}$ s.c. reversed withdrawal from a chronic nicotine infusion as measured by elevations in intracranial self-stimulation thresholds whereas 4-hr WBE producing similar brain nicotine levels did not. These data demonstrate the feasibility of delivering cigarette smoke to rats at clinically relevant doses, and provide preliminary evidence that the behavioral effects of nicotine delivered in smoke may differ from those of pure nicotine.
\end{abstract}

\section{Keywords}

Cigarette smoke; nicotine; pharmacokinetics; locomotor sensitization; intracranial self-stimulation; withdrawal; rat

\footnotetext{
Corresponding Author: Andrew C. Harris, Ph.D., Minneapolis Medical Research Foundation, 914 South $8^{\text {th }}$ St., S-3 Labs, 860 , Minneapolis, MN 55404, harr0547@umn.edu, Telephone: 612-250-0863, Fax: 612-337-7372.

The authors have no financial conflicts of interest to report.

Publisher's Disclaimer: This is a PDF file of an unedited manuscript that has been accepted for publication. As a service to our customers we are providing this early version of the manuscript. The manuscript will undergo copyediting, typesetting, and review of the resulting proof before it is published in its final citable form. Please note that during the production process errors may be discovered which could affect the content, and all legal disclaimers that apply to the journal pertain.
} 


\section{Introduction}

Animal models of tobacco dependence typically rely on parenteral (i.v., s.c., or i.p.) administration of nicotine administered alone (i.e., "pure nicotine", Lerman et al., 2007; Mathieu-Kia et al., 2002; O'Dell and Khroyan, 2009). While these models have been invaluable in characterizing nicotine's neuropharmacological and behavioral effects, they do not fully simulate nicotine exposure in humans via inhalation of cigarette smoke. Aspects of nicotine pharmacokinetics that play an important role in tobacco dependence (e.g., rate and extent of nicotine delivery to brain) can differ substantially if nicotine is inhaled rather than administered parenterally (e.g., Henningfield et al., 1993; Rose et al., 1999). In addition, while nicotine is the primary addictive component of tobacco (Benowitz, 2008; U.S. Department of Health and Human Services, 1999), certain non-nicotine smoke constituents (e.g., monoamine oxidase (MAO) inhibitors) may also contribute to tobacco dependence (Belluzzi et al., 2005; Dwoskin et al., 1999; Guillem et al., 2005). Finally, certain sensory stimuli that contribute to smoking behavior (e.g., smoke smell, taste, Rose, 2006; Rose et al., 1993) are not reproduced in parenteral models. These differences make it difficult to fully understand the pharmacology of tobacco smoke, and may contribute to the imperfect predictive clinical validity of current animal models of tobacco dependence (see Lerman et al., 2007).

Animal models using cigarette smoke exposure might more closely simulate some important aspects of nicotine exposure in smokers. Cigarette smoke inhalation systems involving either nose-only exposure (NOE) or whole-body exposure (WBE) have been used extensively to study tobacco carcinogenicity and toxicity in animals (Coggins, 2007; Farkas et al., 2006; Hecht, 2005), but only a few preclinical studies have examined the behavioral effects of smoke. Similar to pure nicotine administered parenterally (e.g., Sahley and Berntson, 1979), NOE or WBE to cigarette smoke produced diminished pain sensitivity (analgesia) in rats, with the development of tolerance following repeated exposures (Anderson et al., 2004; Mousa et al., 1988; Simons et al., 2005). Repeated WBE to smoke also induced locomotor sensitization (LMS, Suemaru et al., 1992). Small et al (2010) recently reported that repeated WBE to smoke induced nicotine dependence as measured by antagonist-precipitated elevations in intracranial self-stimulation (ICSS) thresholds (a measure of anhedonia associated with nicotine withdrawal, Epping-Jordan et al., 1998) and somatic withdrawal signs, and also suppressed operant responding for both i.v. nicotine infusions and food. Not all studies have reported similar behavioral effects of cigarette smoke and pure nicotine, as spatial memory and swimming endurance in rats were enhanced by s.c. nicotine but inhibited by smoke (Battig, 1970; Hrubes and Battig, 1970; Nowakowska et al., 2006).

These studies illustrate the feasibility of applying smoke exposure methodology to animal behavioral models. However, most have used smoke exposure conditions that produce serum nicotine levels $\geq 100 \mathrm{ng} / \mathrm{ml}$ (compared to a range of $10-60 \mathrm{ng} / \mathrm{ml}$ in smokers, Benowitz et al., 1982; Hurt et al., 1993; Russell et al., 1980) and blood levels of carboxyhemoglobin (COHgb; a measure of carbon monoxide exposure) of 15-35\% (compared to $\leq 10 \%$ in smokers, Benowitz et al., 1982; Cronenberger et al., 2008). In addition to these limitations, such intense exposure conditions may produce non-specific pharmacological or toxic effects (e.g., tail tremor, sedation, see Gomita et al., 1991a; Gomita et al., 1991b; Suemaru et al., 1992) that complicate data interpretation.

The primary goal of this study was to develop and validate methods for administering cigarette smoke to rats using NOE and WBE conditions that were both clinically relevant (i.e., produced serum nicotine and blood $\mathrm{COHgb}$ levels similar to those in smokers) and behaviorally relevant (i.e., produced brain nicotine levels similar to those produced by behaviorally active doses of pure nicotine). Secondarily, pilot studies of smoke effects on behavior were conducted. The potential for repeated NOE to induce LMS was examined. NOE was used because LMS is 
most robust under conditions of brief, rapid onset nicotine administration (Samaha et al., 2005), and NOE produces target smoke exposure concentrations at a substantially faster rate than WBE. The WBE methodology, which avoids restraint stress associated with NOE and is better suited for longer exposures and attainment of higher nicotine exposure levels (e.g., Chen et al., 1995), was used to examine whether acute exposure to smoke could decrease ICSS thresholds (reflecting an enhancement of brain reinforcement function), a well-established effect of nicotine and other addictive drugs (Bauco and Wise, 1994; Harrison et al., 2002; Huston-Lyons and Kornetsky, 1992). The potential for WBE to smoke to reverse withdrawal from a chronic nicotine infusion as measured by elevations in ICSS thresholds was also examined. Doses of pure nicotine administered parenterally and producing brain nicotine levels within the range of those produced by smoke were used as positive controls.

\section{Materials and Methods}

\subsection{Animals}

Male Holtzman Sprague Dawley rats (Harlan, Indianapolis, IN) weighing 275-325 g at the time of arrival were housed individually in temperature- and humidity-controlled colony rooms with unlimited access to water. Rats in Experiments 1 and 2 were housed under a regular 12$\mathrm{hr}$ light/dark cycle and tested during the light (inactive) phase. Rats in Experiment 3 were housed under a reversed 12-hr light/dark cycle so that ICSS testing would occur during the dark (active) phase, as is standard in our laboratory and others (Roiko et al., 2009; Skjei and Markou, 2003). Beginning one week after arrival, all rats were food-restricted to $\approx 18 \mathrm{~g} /$ day rat chow to maintain good health and to prevent rats in NOE experiments from becoming too large to fit in the NOE restraint bottles. Protocols were approved by the Minneapolis Medical Research Foundation Animal Care and Use Committee and were in compliance with the National Institutes of Health Guide for Care and Use of Laboratory Animals (Publication No. 85-23, revised 1985).

\subsection{Drugs}

Nicotine bitartrate (Sigma Chemical Co., St. Louis, MO) was dissolved in sterile saline. The $\mathrm{pH}$ of the nicotine solution was adjusted to 7.4 with dilute $\mathrm{NaOH}$. Nicotine doses are expressed as that of the base.

\subsection{Cigarettes}

2R4F research cigarettes (University of Kentucky) containing $13 \mathrm{mg}$ nicotine/cigarette (our determination) and with a Federal Trade Commission (FTC) method smoke yield of $0.8 \mathrm{mg}$ nicotine and $9.2 \mathrm{mg}$ tar (comparable to a commercial filter cigarette, Counts et al., 2006) were used.

\subsection{Cigarette smoke exposure system}

The smoke exposure system (TSE systems, Bad Homburg, Germany) consisted of a computercontrolled smoke generator that fed a mixture of mainstream smoke and air to the NOE or WBE apparatus. The smoke generator held 10 cigarettes in a rotary device which lit and presented cigarettes to a syringe that withdrew $35 \mathrm{ml}$ of smoke over $2 \mathrm{sec}$, duplicating the FTC smoking machine puffing method (e.g., Byrd et al., 1995). Smoke was pumped into a mixing chamber where it was diluted with fresh air at a rate of $15 \mathrm{~L} / \mathrm{min}$ (NOE) or $80 \mathrm{~L} / \mathrm{min}$ (WBE) and driven through the NOE or WBE apparatus by controlled negative pressure. For NOE, smoke was directed to an eight-port cylinder (interior volume $=350 \mathrm{ml}$ ) that accepted glass $\mathrm{NOE}$ restraint bottles (interior volume $=800 \mathrm{ml}$ ). Rats were restrained so that their noses rested in and largely occluded the exposure ports. For WBE, smoke was directed to an airtight box $(60 \times 90 \times 90 \mathrm{~cm})$ containing wire cages $(28 \times 20 \times 15 \mathrm{~cm})$ in which rats were placed. Smoke was 
delivered at a rate of either 4 (NOE) or 10 (WBE) puffs/min (reflecting the puff rate of the automated syringe). Each cigarette was puffed 6 times before replacement. Smoke quality was monitored using in-line oxygen, carbon monoxide, pressure, and flow rate sensors.

\subsection{Experiment 1: Nicotine pharmacokinetics following NOE and WBE to cigarette smoke}

\subsubsection{Protocols}

2.5.1.1. Experiment 1A: Serum and brain nicotine levels following 10- or 45-min NOE to smoke or s.c. nicotine $(\mathbf{0 . 1} \mathbf{~ m g} / \mathbf{k g})$ : Rats were implanted with a jugular catheter under droperidol ( $2 \mathrm{mg} / \mathrm{kg}) /$ fentanyl $(0.04 \mathrm{mg} / \mathrm{kg}$ ) anesthesia (LeSage et al., 2002). Two days later, rats were placed in the NOE restraint bottles and exposed to smoke for either $10 \min (n=6)$ or $45 \mathrm{~min}(\mathrm{n}=8)$. Duration of NOE was limited to $45 \mathrm{~min}$ to avoid eye irritation (unpublished observations). Immediately following exposure, rats were rapidly anesthetized with i.v. methohexital sodium $(2 \mathrm{mg})$ and blood was obtained via the catheter. Rats were then decapitated and brains were rapidly removed, rinsed, and frozen. An additional group of catheterized rats (Nic $0.1 ; \mathrm{n}=8$ ) was injected with s.c. nicotine $0.1 \mathrm{mg} / \mathrm{kg}$ (i.e., the dose used to induce LMS in the positive control group in Experiment 2) and blood and brain collected 10 min later. Samples were collected near the time at which peak serum and brain nicotine levels should occur following NOE and s.c. nicotine (Ghosheh et al., 1999; Pratt et al., 1983; Rotenberg and Adir, 1983; Rotenberg et al., 1980). Timing of sample collection also coincided with the timing of behavioral testing (see below). Rats receiving s.c. nicotine were placed in the NOE restraint bottles and exposed to air alone between injection and sample collection to more closely simulate conditions of the smoke-exposed groups and to control for potential effects of restraint stress on nicotine pharmacokinetics (Winders et al., 1998). An additional group (Air Alone; $n=6$ ) was treated as described for the Nic 0.1 group with the exception that rats did not receive nicotine injections.

2.5.1.2. Experiment 1B: Time course of serum nicotine levels following 45-min NOE to smoke: Serum nicotine levels following smoke exposure have been reported to decline at a much slower rate than expected based on the $\approx 1 \mathrm{hr}$ elimination half-life of nicotine in rats (Anderson et al., 2004; Rotenberg and Adir, 1983), presumably due to rats grooming and ingesting residual nicotine on their fur following smoke exposure. Given that LMS is most robust when nicotine is administered as a rapid bolus (Samaha et al., 2005), such an effect could inhibit the potential for repeated 45-min NOE to induce LMS in Experiment 2. To examine the time course of serum nicotine levels following 45-min NOE, unanesthetized rats $(\mathrm{n}=7)$ received 45 -min NOE to smoke and blood samples were collected via an i.v. catheter $0 \mathrm{hr}, 1 \mathrm{hr}, 6 \mathrm{hr}$, and $24 \mathrm{hr}$ following exposure.

2.5.1.3. Experiment 1C: Serum and brain nicotine levels following 1-, 2-, or 4-hr WBE to smoke or s.c. nicotine $(\mathbf{0 . 1 2 5} \mathbf{~ m g} / \mathbf{k g})$ : Rats were placed in the WBE chambers and exposed to cigarette smoke for an initial 45 min equilibration period during which smoke concentrations in the exposure chamber increased to a plateau, followed by another $1 \mathrm{hr}(\mathrm{n}=4), 2 \mathrm{hr}(\mathrm{n}=4)$, or $4 \mathrm{hr}(\mathrm{n}=8)$ of smoke exposure at this level. Immediately following exposure, rats were anesthetized with s.c. droperidol/fentanyl and blood was obtained via cardiac puncture. Cardiac puncture was used because i.v. cannulae can become externally contaminated with nicotine during WBE (unpublished observations). Rats were then decapitated and brains collected. An additional group (Pure Nic 0.125; $\mathrm{n}=7$ ) was injected with s.c. nicotine $0.125 \mathrm{mg} / \mathrm{kg}$ (i.e., the dose used to reverse nicotine withdrawal in the positive control group in Experiment 3) and blood and brain were collected 10 min later.

2.5.2. Nicotine and $\mathrm{COHgb}$ assay-Serum and brain nicotine levels were measured by gas chromatography with nitrogen-phosphorous detection (Jacob et al., 1981). Brain nicotine 
concentrations were corrected for brain blood content (Hieda et al., 1999). Blood COHgb levels were determined using a blood gas analyzer (Block Scientific, Inc., Nutley, NJ).

\subsection{Experiment 2: Effects of repeated $45-\mathrm{min}$ NOE to smoke on locomotor activity}

2.6.1. Equipment-Locomotor monitoring sessions were conducted in $43 \times 43 \mathrm{~cm}$ open field activity chambers (Med Associates, Inc., St. Albans, VT). Each chamber had two 16beam photocell arrays placed $5 \mathrm{~cm}$ and one array $18 \mathrm{~cm}$ above the chamber floor to monitor horizontal and vertical activity, respectively. Chambers were placed inside sound-attenuating cubicles that had exhaust fans providing masking noise and ambient lighting. Open-field activity software (Med Associates) was used for operating the apparatus and recording data.

\subsubsection{Protocols}

2.6.2.1. Phase 1: Habituation (test days -1 and 0): On each of two consecutive days, all rats $(\mathrm{N}=21)$ were tested for locomotor activity for $30 \mathrm{~min}$ (pre-exposure test) and, five min later, placed in the NOE restraint bottles and exposed to air alone for $45 \mathrm{~min}$. Five min later, rats were injected with s.c. saline and immediately tested for locomotor activity for $30 \mathrm{~min}$ (postexposure test). Total distance traveled during the post-exposure test on the second day of Habituation was used to match animals into groups (see below) with similar baseline activity levels.

2.6.2.2. Phase 2: Sensitization (test days 1-14): This phase began two days after completion of Habituation. On each test day, rats in the Air + Sal group (negative control, $n=7$ ) continued to be treated as during Habituation (i.e., $30 \mathrm{~min}$ pre-exposure test, $45 \mathrm{~min}$ NOE to air alone, s.c. saline injection, 30 min post-exposure test). The Air + Nic 0.1 group (positive control, $n$ $=6)$ was treated identically with the exception that rats were injected with s.c. nicotine $(0.1$ $\mathrm{mg} / \mathrm{kg}$ ) rather than saline prior to the post-exposure test. This nicotine dose has been shown to induce LMS (Clarke and Kumar, 1983a; Domino, 2001). The Smoke + Sal group $(\mathrm{n}=7)$ was treated as described for the Air + Sal group with the exception that rats received 45-min NOE to smoke, an exposure duration that produced brain nicotine levels within the range of those produced by the $0.1 \mathrm{mg} / \mathrm{kg}$ nicotine dose (see Results). Rats were treated in this manner for a total of 14 test days, which occurred on consecutive days with the exception of a two-day weekend break between test days 5 and 6 and a three-day break between test days 10 and 11 .

2.6.2.3. Phase 3: Nicotine Challenge (challenge days 1-5): This phase examined whether the experimental history of the groups influenced their development of LMS to pure nicotine. Two days after completion of the Sensitization phase, all rats were tested for activity for 30 $\min$ (pre-exposure test), immediately injected with nicotine $(0.3 \mathrm{mg} / \mathrm{kg}$, s.c.), and again tested for activity for $30 \mathrm{~min}$ (post-exposure test). This procedure was repeated each day for five consecutive days. This nicotine dose was used because it induces robust LMS following only a small number of exposures (e.g., Miller et al., 2003), allowing for a shorter protocol than if a lower (e.g., $0.1 \mathrm{mg} / \mathrm{kg}$ ) dose was used. Rats were not placed in the NOE restraint bottles during this phase.

\subsection{Experiment 3: Effects of 4-hr WBE to smoke on baseline and withdrawal-induced changes in ICSS thresholds}

2.7.1. Equipment-ICSS testing occurred in operant conditioning chambers $(29 \mathrm{~cm} \times 26$ $\mathrm{cm} \times 33 \mathrm{~cm}$ ) (Med Associates) placed inside sound-attenuated cubicles. A 5-cm wide metal wheel manipulandum was fixed to the front wall. Brain stimulation was administered with constant-current stimulators (Model \#PHM-152, Med-Associates). Rats were connected to the stimulation circuit through bipolar leads (Plastics One, Roanoke, VA) attached to gold-contact 
swivel commutators (Plastics One). MED-PC IV software was used to control stimulation parameters and for data collection.

2.7.2. Stereotaxic surgery-Animals were anesthetized with i.m. ketamine $(75 \mathrm{mg} / \mathrm{kg})$ and xylazine $(7.5 \mathrm{mg} / \mathrm{kg}$ ) and implanted with a bipolar stainless steel electrode (Plastics One) in the medial forebrain bundle at the level of the lateral hypothalamus as described in Roiko et al. (2009). Animals were allowed to recover for at least one week prior to ICSS training. During the first two days of recovery all animals received i.m. injections of the antibiotic ceftriaxone $(5.25 \mathrm{mg})$.

2.7.3. Intracranial self-stimulation training procedure-Rats were trained on a modified version of the Kornetsky and Exposito (1979) discrete-trial current-threshold procedure as described previously (Markou and Koob, 1992). Each trial was initiated with presentation of a non-contingent stimulus $(0.1 \mathrm{~ms}$ cathodal squarewave pulses at a frequency of $100 \mathrm{~Hz}$ for $500 \mathrm{~ms}$ ) followed by a 7.5-sec window during which a positive response on the wheel manipulandum produced a second, contingent stimulation identical to the first. Lack of responding in the 7.5-sec window was considered a negative response. Each positive or negative response was followed by a variable inter-trial interval averaging $10 \mathrm{sec}$ (range $=7.5$ to $12.5 \mathrm{sec}$ ), during which time additional responses delayed onset of the subsequent trial by $12.5 \mathrm{sec}$. Stimulus intensities were presented in four alternating descending and ascending series ( step size $=5 \mathrm{uA}$ ), with five trials presented at each current intensity step. The current threshold for each series was defined as the midpoint between two consecutive intensity steps that yielded three or more positive responses and two consecutive intensity steps that yielded three or more negative responses. The overall threshold for the $\approx 45 \mathrm{~min}$ session was defined as the mean of the current thresholds from the four alternating series. To assess performance effects (e.g., motor disruption), response latencies (time between onset of the non-contingent stimulus and a positive response) were averaged across all trials in which a positive response was made.

\subsubsection{Protocols}

\subsubsection{Phase 1: Effects of 4-hr WBE to cigarette smoke on baseline ICSS thresholds:} Rats ( $\mathrm{N}=18)$ were trained for ICSS in twice daily sessions ( $6 \mathrm{hr}$ break between sessions) until thresholds were stable (i.e., no more than $10 \%$ coefficient of variation over a 5 -day period). Rats were then divided into three experimental groups with similar mean baseline thresholds. On each of two Habituation days, all rats were tested for ICSS (pre-exposure test) and, $1 \mathrm{hr}$ later, received WBE to air alone for $4 \mathrm{hr}$. All rats were then administered s.c. saline and, 10 min later, again tested for ICSS (post-exposure test). The purpose of the saline injections was to more closely simulate the conditions of Phase 2 (see below). This procedure (i.e., preexposure test, $4 \mathrm{hr}$ WBE to air alone, s.c. saline, post-exposure test) will be referred to as Air + Sal exposure. The following day (test day), Group $1(n=6)$ was exposed to Air + Sal as on Habituation days (see Fig 1, Phase 1). Groups 2 and $3(n=6$ each) were treated identically with the exception that they received $4 \mathrm{hr}$ WBE to smoke between the pre- and post-exposure tests as described above (i.e., Smoke + Sal exposure, see Fig 1, Phase 1). Both Groups 2 and 3 were exposed to smoke during this Phase so that their experimental history would be identical prior to withdrawal testing in Phase 2.

2.7.4.2. Phase 2: Effects of 4-hr WBE to cigarette smoke and s.c. nicotine $(0.125 \mathrm{mg} / \mathrm{kg})$ on nicotine withdrawal-induced increases in ICSS thresholds: Following completion of Phase 1, rats continued to be tested for ICSS for at least 2 weeks and until thresholds were stable. Rats were then implanted s.c. with Alzet 2ML2 osmotic minipumps (Durect, Cupertino, CA) delivering a continuous infusion of either saline (Group 1) or nicotine $(3.2 \mathrm{mg} / \mathrm{kg} / \mathrm{day}$; Groups 2 and 3) as described in Roiko et al. (2009). This infusion rate reliably induces nicotine 
dependence as measured by elevated ICSS thresholds following pump removal (i.e., spontaneous withdrawal, Epping-Jordan et al., 1998). Rats continued to be tested for ICSS during saline / nicotine exposure. All rats were tested under Habituation (i.e., Air + Sal) conditions on days 6 and 7 following pump implantation. Pumps were removed immediately following the post-exposure test on day 7 to elicit spontaneous withdrawal.

The following day (withdrawal day), Group 1 (negative control) was exposed to Air + Sal (see Fig 1, Phase 2, Withdrawal 1). To examine the potential for s.c. nicotine to reverse nicotine withdrawal-induced increases in ICSS thresholds, half of the rats in Group 2 were exposed to air alone for $4 \mathrm{hr}$ followed by s.c. injection of nicotine $(0.125 \mathrm{mg} / \mathrm{kg}) 10 \mathrm{~min}$ prior to the posttest (i.e., Air + Nic 0.125 exposure, Fig 1, Phase 2, Withdrawal 1). This nicotine dose was used because it effectively reverses withdrawal from a chronic nicotine infusion as measured using somatic signs (Malin et al., 1992;1996;2001). The other half of Group 2 was exposed to Air + Sal to confirm the occurrence of spontaneous withdrawal at this time point (i.e., $23 \mathrm{hr}$ following nicotine pump removal), as previously reported (Epping-Jordan et al., 1998). To examine the potential for smoke exposure to reverse the nicotine withdrawal effect on ICSS, half of the rats in Group 3 were exposed to Smoke + Sal (Fig 1, Phase 2, Withdrawal 1). This duration of exposure was used because it produced similar brain nicotine levels as those achieved following s.c. nicotine $0.125 \mathrm{mg} / \mathrm{kg}$ (see Results). The other half of Group 3 was exposed to Air + Sal.

Following completion of the above procedure, all rats continued to be tested for ICSS for at least 2 weeks and until stable. Group 1 then underwent the same procedure as described above (i.e., chronic saline infusion for 7 days, Air + Sal exposure on the withdrawal day; see Fig 1, Phase 2, Withdrawal 2). Groups 2 and 3 were also treated as described above, but with the exposure conditions crossed over between each half of the group (see Fig 1, Phase 2, Withdrawal 2 for Groups 2 and 3). Similar within-subject cross-over designs have been used to study the effects of pharmacological treatments on withdrawal from nicotine and other drugs (e.g., Bruijnzeel et al., 2009;George et al., 2007;Harris et al., 2006;Rothwell et al., 2009).

Differences in withdrawal severity across the two withdrawal assessments should not complicate data interpretation, as Skjei et al (2003) reported similar withdrawal magnitude across repeated (up to four) spontaneous withdrawal episodes using the same nicotine infusion dose, exposure duration, and withdrawal measure (i.e., elevations in ICSS thresholds) as used in this study.

2.7.4.3. Phase 3: Effects of s.c. nicotine on baseline ICSS thresholds: The lack of effect of 4-hr WBE to smoke on baseline ICSS thresholds during Phase 1 (see Results) contrasts with the well-established threshold-lowering effects of pure nicotine (e.g., Harrison et al., 2002; Huston-Lyons and Kornetsky, 1992). The purpose of this phase was to confirm that s.c. nicotine would reduce thresholds in these same animals. Following completion of Phase 2, Groups 2 and 3 continued to be tested for ICSS for at least 2 weeks and until thresholds were stable. All rats were then exposed to Air + Sal on each of two Habituation days as described above. Rats then underwent a total of 4 test sessions, with a minimum of 3 days and a return of thresholds to baseline levels between tests. During test sessions 1-3, rats were exposed to $4 \mathrm{hr}$ Air + Sal or $4 \mathrm{hr}$ Air + Nic $(0.125,0.25$, or $0.50 \mathrm{mg} / \mathrm{kg}$ nicotine; see Fig 1, Phase 3, Nicotine Dose-

Response). Injections occurred $10 \mathrm{~min}$ prior to the post-test. This range of nicotine doses has been reported to reduce baseline ICSS thresholds (e.g., Harrison et al., 2002) and includes the $0.125 \mathrm{mg} / \mathrm{kg}$ dose that produced similar brain nicotine levels as 4-hr WBE to smoke. Due to limited equipment availability, only two of the three nicotine doses could be tested in each rat. However, dosing was counterbalanced so that the same number of rats were exposed to each dose. Following completion of the nicotine dose-response function, all rats were exposed to Smoke + Sal on test day 4 to provide a replication of smoke exposure testing (see Fig 1 , Phase 3, Smoke + Sal Replication). 


\subsection{Statistical analyses}

2.8.1. Experiment 1: Nicotine pharmacokinetics following NOE and WBE to cigarette smoke-Mean serum nicotine concentrations, brain nicotine concentrations, and brain:serum nicotine concentration ratios in the Nic 0.1, 10-min NOE, and 45-min NOE conditions were analyzed using separate one-way ANOVAs (normally distributed data) or Kruskal-Wallace tests (non-normally distributed data) with group (exposure condition) as a factor, followed by Dunnett's or Dunn's post hoc test comparing the NOE groups to the Nic 0.1 group (Fig 2A-2C). Data from the 1-,2-, and 4-hr WBE groups were compared to data from the Nic 0.125 group in a similar manner (2D-2F). If nicotine sample contamination was evident (defined as a value $>2.5 \mathrm{SD}$ from the mean), all data for that animal were removed ( 2 out of a total of 153 samples).

\subsubsection{Experiment 2: Effects of repeated 45-min NOE to smoke on locomotor} activity-Locomotor activity was measured as total horizontal distance traveled (in $\mathrm{cm}$ ) over each 30-min session. Data during the pre- and post-exposure tests during Habituation and Sensitization phases were analyzed using separate 2-way ANOVAs with group and test day as factors, followed by Bonferroni post tests for between-group comparisons on each test day (Fig 3A). To assess whether groups exhibited sensitization (defined as a significant increase in activity across repeated drug exposures, DiFranza and Wellman, 2007; Robinson and Berridge, 1993), separate one-way ANOVAs were used to compare post-exposure activity levels within each group during the first (test day 1) and final (test days 11-14) days of Sensitization, followed by Dunnett's post-test comparing test day 1 to each of test days 11-14. To evaluate whether collapsing data across each 30 min session obscured effects of smoke during Sensitization, within-session activity during the first (test day 1) and final (test day 14) days of Sensitization were separated into 5-min blocks and analyzed using separate two-factor ANOVAs with group and 5-min block as factors (Fig 3B and 3C). When appropriate, Bonferroni post tests were used for between-group comparisons at each 5-min block. Similar analyses were used to examine between-group differences and extent of sensitization to s.c. nicotine $(0.3 \mathrm{mg} / \mathrm{kg}$ ) during the Nicotine Challenge phase (Fig 4).

\subsubsection{Experiment 3: Effects of 4-hr WBE to smoke on baseline and withdrawal- induced changes in ICSS thresholds}

2.8.3.1. Baseline measures: Baseline ICSS thresholds and response latencies were defined as the mean during the last 5 days prior to either the test day (Phase 1), each of the two withdrawal days (Phase 2), or test day 1 (Phase 3). Only the second session of each baseline day (i.e., the session conducted during the same time of day as post-exposure tests) was used. Baseline threshold and latency data during Phase 2 were compared between the first and second pump exposure in each group using separate paired sample t-tests and subsequently collapsed because they did not differ significantly. Baseline threshold and latency data during Phases 1 and 2 were compared between groups using separate one-way ANOVAs to confirm that they did not differ (Table 1). ICSS threshold and response latency data were computed as percentage of baseline for all subsequent analyses.

2.8.3.2. Phase 1: Thresholds and latencies during the post-exposure test in rats exposed to Smoke + Sal on the test day (i.e., Groups 2 and 3) were compared using separate independent samples t-tests. These data were subsequently collapsed because they did not differ significantly and compared to data from rats exposed to Air + Sal on the test day (i.e., Group 1) using separate independent samples $t$ tests (Fig 5A and 5B).

2.8.3.3. Phase 2: ICSS thresholds and response latencies on each withdrawal day in Group 1 (negative control) were compared across both saline pump/Air + Sal exposures using paired samples t-tests and collapsed for subsequent analyses because they did not differ significantly. 
To confirm the presence of spontaneous withdrawal in nicotine-infused rats (i.e., Groups 2 and 3 ) in the absence of smoke/s.c. nicotine treatment, threshold and latency data following Air + Sal exposure on the withdrawal day were analyzed across groups using separate one-way ANOVAs followed by Dunnett's post hoc tests comparing Groups 2 and 3 to Group 1 (Fig 6). To examine the potential for s.c. nicotine $(0.125 \mathrm{mg} / \mathrm{kg}$, s.c. $)$ and cigarette smoke to reverse withdrawal, threshold and latency data on the withdrawal day following Air + Nic 0.125 exposure (Group 2) or Smoke + Sal exposure (Group 3) were compared to Air + Sal exposure (i.e. spontaneous withdrawal condition) within each group using paired samples t-tests (withinsubject analysis of withdrawal reversal). Data from the Air + Nic 0.125 and Smoke + Sal conditions were also compared to data from Group 1 using one-way ANOVA followed by Dunnett's post hoc tests (between-subject analysis of withdrawal reversal).

2.8.3.3. Phase 3: To examine the effects of s.c. nicotine on baseline ICSS thresholds and response latencies, data from post-exposure tests following each nicotine dose were compared to the Air + Sal condition using paired t-tests with Bonferroni correction (Fig 7). Analysis of variance could not be used due to missing data (i.e., only two of the three s.c. nicotine doses were tested in each rat, see above). To examine the replication of effects of smoke exposure on baseline thresholds and latencies, additional paired t-tests were used to compare threshold and latency data following Smoke + Sal and Air + Sal exposure.

\section{Results}

\subsection{Experiment 1: Nicotine pharmacokinetics following NOE and WBE to cigarette smoke}

3.1.1. Experiment 1A: Serum and brain nicotine levels following 10- or 45-min NOE to smoke or s.c. nicotine $(0.1 \mathbf{~ m g} / \mathbf{k g})$-Administration of smoke via $45-\mathrm{min}$ NOE produced similar serum nicotine levels and brain nicotine levels within the range of those produced by s.c. nicotine $0.1 \mathrm{mg} / \mathrm{kg}$. There was a significant difference in serum nicotine levels between the Nic 0.1, 10-min NOE, and 45-min NOE groups $(F(2,19)=4.2, p<0.05$; Fig 2A), although the Nic 0.1 group did not differ significantly from either the 10-min NOE or 45-min NOE group. There was a significant difference in brain nicotine levels between groups (Kruskal-Wallis $\mathrm{H}=12.9, \mathrm{p}<0.01$ ), with lower brain nicotine levels in the 10-min NOE group than in the Nic 0.1 group ( $<<0.01$; Fig 2B). Brain nicotine levels were somewhat lower in the 45 -min NOE group than in the Nic 0.1 group (see Fig 2B), but this effect was not statistically significant and the range of brain nicotine levels between groups overlapped considerably (Nic 0.1: 101-160 ng/g; 45-min NOE: 46-140 ng/g). There was a significant difference in brain:serum nicotine concentration ratios between groups (Kruskal-Wallis $\mathrm{H}=15.2, \mathrm{p}<0.001$ ), with a higher ratio in the Nic 0.1 group compared to either the 10-min or 45-min NOE groups ( $\mathrm{p}<0.05$ or 0.01 ; Fig 2C). As expected, serum nicotine levels in the Air Alone group were below the level of quantitation $(<2 \mathrm{ng} / \mathrm{ml})$.

\subsubsection{Experiment 1B: Time course of serum nicotine levels following 45-min} NOE to smoke-Serum nicotine levels immediately following 45-min NOE to smoke (Mean \pm SD) were $17 \pm 11 \mathrm{ng} / \mathrm{ml}$. Serum levels were $8 \pm 3 \mathrm{ng} / \mathrm{ml}$ at the 1 -hr test, and were below the limit of quantitation $(<2 \mathrm{ng} / \mathrm{ml})$ at the 6 - and $24-\mathrm{hr}$ tests, indicating minimal oral exposure to nicotine via grooming.

3.1.3. Experiment 1C: Serum and brain nicotine levels following 1-, 2-, or 4-hr WBE to smoke or s.c. nicotine $(0.125 \mathbf{~ m g} / \mathbf{k g})$-Administration of smoke via $4 \mathrm{hr}$ WBE produced higher serum nicotine levels and similar brain nicotine levels compared to those produced by s.c. nicotine $(0.125 \mathrm{mg} / \mathrm{kg})$. There was a significant difference in serum nicotine levels between groups $(F(3,19)=12.1, p<0.0001$; Fig $2 \mathrm{D})$, with higher levels in the 4-hr WBE group compared to the Nic 0.125 group $(\mathrm{p}<0.01)$. There was also a significant difference 
in brain nicotine levels between groups $(F(3,19)=17.4, p<0.0001$; Fig $2 \mathrm{E})$, with lower levels in the 1- and 2-hr WBE groups than in the Nic 0.125 group ( $<<0.01$ ). There was a significant difference in brain:serum nicotine concentration ratios $(F(3,19)=38.8, p<0.0001)$, with a higher ratio in the Nic 0.125 group compared to either the 1-hr, 2-hr, or 4-hr WBE groups (all $p \mathrm{~s}<0.01$; Fig 2F).

\subsubsection{Carbon monoxide and blood $\mathrm{COHgb}$ levels (Experiments $1 \mathrm{~A}$ and $1 \mathrm{C}$ )-}

Carbon monoxide levels of the smoke/air mixture during 10- and 45-min NOE in Experiment $1 \mathrm{~A}$ were outside the range of the $\mathrm{CO}$ meter (i.e., > $300 \mathrm{ppm}$ ) during a significant period of the sessions and are therefore not reported. Blood COHgb levels in the Air Alone and 45-min NOE groups in Experiment 1A (Mean \% $\%$ SD) were $3.0 \pm 0.7 \%$, and $7.6 \pm 1.8 \%$, respectively. Carbon monoxide levels of the smoke/air mixture (Mean ppm $\pm \mathrm{SD}$ ) during 1-hr, 2-hr, and 4$\mathrm{hr}$ WBE in Experiment 1C were $46.5 \pm 5.2,74.0 \pm 8.08$, and 83.4 \pm 0.9 , respectively. Blood $\mathrm{COHgb}$ levels following 1-hr, 2-hr, and 4-hr WBE were $8.5 \pm 0.6 \%, 11.0 \pm 0.8 \%$, and $10.5 \pm$ $1.6 \%$, respectively.

\subsection{Experiment 2: Effects of repeated 45-min NOE to smoke on locomotor activity} 3.2.1. Pre-exposure tests: Habituation, Sensitization, and Nicotine ChallengeOverall (30 min) activity levels during pre-exposure tests did not differ between groups during any session during Habituation, Sensitization, or Nicotine Challenge phases (data not shown), indicating that any between-group differences observed during post-exposure tests were due to drug treatment.

3.2.2. Post-exposure tests: Habituation and Sensitization-Overall activity levels during post-exposure tests did not differ between groups during Habituation (Fig 3A). During Sensitization, there were significant effects of group $(F(2,221)=12.4, p<0.001)$ and test day $F(13,221)=4.2, p<0.0001)$, and a significant interaction $(F(26,221)=1.8, p<0.05)$. Activity in the Air + Nic 0.1 group was higher than in the Air + Sal group on test days 3, 5-7, and 914 (Fig 3A, $\mathrm{t}=2.9-4.7, p<.05$ or .01 ). Activity in the Smoke + Sal and Air + Sal groups did not differ on any test day during Sensitization. Within-group comparison of activity in the Air + Nic 0.1 group indicated a significant effect of test day $(F(4,20)=10.3, p<0.01)$. Activity was higher on each of test days 11-14 compared to test day 1 (Dunnett $q=2.9-4.0, p<0.05$ or 0.01 ; Fig 3A), indicating sensitization. There was no effect of test day for either the Air + Sal or Smoke + Sal groups.

Within-session analyses were consistent with mean activity across the entire 30 min session. There was a significant effect of 5-min block on test day $1(F(5,85)=50.1, p<0.0001)$ but no effect of group or interaction (Fig 3B). On test day 14, there were significant effects of group $(F(2,85)=6.5, p<0.01)$, block $(F(5,85)=37.0, p<0.0001)$, and a group by block interaction $(F(10,85)=2.1, p<0.05)$. Activity in the Air + Nic 0.1 group was higher than in the Air + Sal group during the first 10 min of session $14(t=3.7-4.3, p<0.01$, Fig $3 C)$. Activity in the Air + Sal and Smoke + Sal groups did not differ at any 5-min block.

3.2.3. Post-exposure tests: Nicotine Challenge-A history of repeated exposure to nicotine $(0.1 \mathrm{mg} / \mathrm{kg}$, s.c. $)$, but not $45-\mathrm{min}$ NOE, enhanced the initial locomotor-activating effects of repeated s.c. nicotine injections $(0.3 \mathrm{mg} / \mathrm{kg})$. There were significant effects of group $(F(2,68)=6.5, p<0.01)$ and challenge day $(F(4,68)=16.5, p<0.0001)$, but no group by challenge day interaction. Activity in rats previously exposed to Air + Nic 0.1 was higher than in rats previously exposed to Air + Sal on each of challenge days $1-4(t=2.8-3.6, p<0.05$ or 0.01 ), but not on challenge day 5 (Fig 4). The Smoke + Sal and Air + Sal pre-exposed groups did not differ on any challenge day. Within-group analyses indicated significant effects of challenge day for all groups (Air + Sal history: $F(4,24)=12.7, p<0.0001$; Air + Nic 0.1 
history: $F(4,20)=3.3, p<0.05$; Smoke + Sal history: $F(4,24)=5.0, p<0.01)$. Activity for all groups was higher on challenge days 3,4 , and/or 5 compared to challenge day $1(\mathrm{t}=2.7-$ $6.5, \mathrm{p}<0.05$ or $0.01 ; \mathrm{Fig} 4)$, indicating that rats sensitized to s.c. nicotine $(0.3 \mathrm{mg} / \mathrm{kg})$ regardless of experimental history.

\subsection{Experiment 3. Effects of 4-hr WBE to smoke on baseline and withdrawal-induced changes in ICSS thresholds}

\subsubsection{Baseline ICSS thresholds and response latencies (Phases 1 and 2)-}

Baseline ICSS thresholds and response latencies did not differ between groups during either Phase 1 or Phase 2 (Table 1), indicating that any between-group differences observed during post-exposure tests on test days/withdrawal days were due to drug treatment.

\subsubsection{Phase 1: Effects of 4-hr WBE to smoke on baseline ICSS thresholds-}

Exposure to Smoke + Sal on the test day did not affect ICSS thresholds in Groups 2 and 3 compared to rats exposed to Air + Sal (i.e., Group 1; Fig 5A). Smoke + Sal exposure did produce a significant decrease in response latencies compared to Air + Sal exposure (Fig $5 \mathrm{~B} ; t(12)=$ $2.2, p<.05)$.

3.3.3. Phase 2: Effects of 4-hr WBE to cigarette smoke and s.c. nicotine (0.125 $\mathrm{mg} / \mathrm{kg}$ ) on nicotine withdrawal-induced increases in ICSS thresholds-There was a significant effect of group on thresholds following Air + Sal exposure on the withdrawal day $(F(2,15)=5.8, p<.05)$. Thresholds in Groups 2 and 3 (i.e., nicotine-exposed rats) following Air + Sal exposure were significantly elevated compared to thresholds in Group 1(salineexposed rats, negative control $)(q=2.9-3.0, p<.05$; see Fig 6$)$, confirming the presence of spontaneous withdrawal. Nicotine $(0.125 \mathrm{mg} / \mathrm{kg}$, s.c.) effectively reversed withdrawal, as thresholds in Group 2 following Air + Nic 0.125 were significantly reduced compared to Air + Sal exposure (i.e., spontaneous withdrawal condition) in these same animals $(t(5)=2.8, p$ $<.05$ ), and also did not differ from thresholds in Group 1. Smoke exposure did not reverse withdrawal (Fig 6), as thresholds in Group 3 following Smoke + Sal exposure did not differ from Air + Sal exposure in these same animals, and were also elevated compared to thresholds in Group 1 (Effect of group $=F(2,15)=3.8, p<.05$; Dunnett's q $=2.6, \mathrm{p}<0.05)$. Response latencies in Groups 2 and 3 did not differ significantly from those in Group 1 under any condition during this Phase (data not shown).

3.3.4. Phase 3: Effects of s.c. nicotine on baseline ICSS thresholds-Three rats did not complete this phase due to loss of headcap, loss of stable thresholds, or other problem. These data have been excluded. Baseline thresholds and response latencies were $77.5 \pm 5.5 \mathrm{uA}$ and $2.6 \pm 0.2 \mathrm{sec}$, respectively. All s.c. nicotine doses tended to decrease thresholds compared to Air + Sal exposure (Fig 7), although this effect was only significant for the $0.25 \mathrm{mg} / \mathrm{kg}$ dose $(t(5)=3.7, p<.05)$. None of the nicotine doses affected response latencies compared to Air + Sal (data not shown). As observed during Phase 1, exposure to Smoke + Sal did not affect baseline thresholds (Fig 7) but did reduce response latencies compared to Air + Sal (mean \% change in latency \pm SEM $=95.05 \pm 1.7 \%$ versus $101.9 \pm 2.6 \% ; t(8)=3.6, p<.01$; data not shown graphically).

\section{Discussion}

The primary goal of this study was to establish clinically and behaviorally relevant smoke exposure conditions. Prior studies have developed rodent cigarette smoke exposure methods, but serum and brain nicotine or carboxyhemoglobin levels were generally not measured or were substantially higher than those associated with cigarette smoking. In the current study, the 10-min NOE condition produced venous serum nicotine levels $(14 \mathrm{ng} / \mathrm{ml})$ similar to those 
in humans smoking 1-2 cigarettes (Benowitz et al., 1988; Henningfield and Keenan, 1993; Herning et al., 1983). Serum nicotine levels $(25-55 \mathrm{ng} / \mathrm{ml})$ and blood COHgb $(7-10 \%)$ in the 45-min NOE and 1-4 hr WBE conditions were within the range of those occurring mid-day in moderate to heavy smokers (Benowitz et al., 1982; Cronenberger et al., 2008; Hurt et al., 1993; Russell et al., 1980). Brain nicotine levels following smoke exposure were either somewhat lower (45-min NOE) or nearly identical (4-hr WBE) to those produced by behaviorally active dose of s.c. nicotine. Thus these exposure conditions provide a reliable and safe means of exposing rats to clinically and behaviorally relevant serum and brain levels of nicotine, and could be used to study other aspects of smoke exposure (e.g., neuropharmacological effects) in future studies.

Although serum and brain nicotine levels following smoke exposure were within the desired range, the brain:serum nicotine ratio was higher for s.c. nicotine than for either NOE or WBE to smoke. It was therefore not possible to match parenteral and inhaled nicotine with regard to both serum and brain nicotine levels, a potential limitation to this design. We chose to match brain nicotine levels across exposure routes as closely as possible (measured at times corresponding to performance of the behavioral studies), since the behavioral effects of nicotine are primarily centrally mediated (e.g., Clarke and Kumar, 1983b; Vezina et al., 2007; Watkins et al., 2000). The reason for the difference in brain:serum nicotine concentration ratios is not clear. However, only one time point was studied and more complete time course information would be helpful in assessing its cause and importance.

While the primary purpose of this study was development of exposure methodology, it also provided a preliminary characterization of the effects of smoke in several animal behavioral models. By several measures, effects of inhaled smoke differed from those of s.c. nicotine.

Repeated 45-min NOE to smoke did not induce LMS or influence the subsequent development of LMS to s.c. nicotine $(0.3 \mathrm{mg} / \mathrm{kg})$. In contrast, a dose of s.c. nicotine $(0.1 \mathrm{mg} / \mathrm{kg})$ producing brain nicotine levels within the range of those produced by 45 -min NOE induced LMS and enhanced the initial locomotor-activating effects of subsequent s.c. nicotine $(0.3 \mathrm{mg} / \mathrm{kg})$. Fourhr WBE to smoke did not enhance brain reinforcement function (i.e., decrease baseline ICSS thresholds) or reverse withdrawal from a chronic nicotine infusion (measured as increases in ICSS thresholds). However, a dose of s.c. nicotine $(0.125 \mathrm{mg} / \mathrm{kg})$ producing similar brain nicotine levels as 4-hr WBE effectively reversed withdrawal. This dose also tended to reduce baseline ICSS thresholds, although this effect only achieved statistical significance when a higher nicotine dose was used.

The different behavioral effects of inhaled smoke and pure nicotine may have been at least partly due to differences in the pharmacokinetics of nicotine delivered via inhalation versus s.c. injection. For example, s.c. nicotine produces peak serum and brain nicotine levels 5-15 min after injection (Ghosheh et al., 1999; Pratt et al., 1983), while the 45-min NOE and 4-hr WBE presumably produced peak serum and brain nicotine levels at the end of smoke exposure. This difference in rate of administration between exposure routes may be important because LMS and certain other behavioral effects of nicotine are most robust when nicotine is administered rapidly (see Samaha et al., 2005; Wakasa et al., 1995). Therefore matching the peak brain nicotine levels may not in itself be sufficient for comparing effects of smoke and s.c. nicotine exposure, and further studies focusing on this question would be of interest. This issue highlights not only the challenges of comparing smoke inhalation with parenteral nicotine exposure in animals, but also the potential limitations of using parenteral administration of pure nicotine in animals to model smoking in humans.

Other aspects of smoke exposure, including the presence of non-nicotine constituents, may have also contributed to the lack of behavioral effects of smoke. This may initially seem unlikely, as the behaviorally active non-nicotine constituents of smoke identified to date (e.g., 
MAO inhibitors) typically enhance nicotine's behavioral effects in rats (Belluzzi et al., 2005; Dwoskin et al., 1999; Guillem et al., 2005). However, these effects have been demonstrated in isolation from the thousands of other chemicals in cigarette smoke, some of which could oppose the effects of nicotine and/or other behaviorally active constituents. Sensory stimuli associated with smoke exposure (e.g., smoke taste, smell) may have also influenced behavior in this study.

It is unlikely that the current findings were influenced by non-specific effects of carbon monoxide in smoke, as blood COHgb levels in all exposure conditions were substantially lower than those producing behavioral suppression in rats (Brunssen et al., 2003; Miyagawa et al., 1995; Rowan and Fountain, 1991). The reduction in baseline ICSS response latencies following $4 \mathrm{hr}$ WBE to smoke instead suggests a stimulatory rather than inhibitory effect on motor performance. The LMS data were not likely influenced by rats ingesting residual nicotine from their fur following smoke exposure, because serum nicotine levels declined rapidly after 45min NOE. It is also unlikely that procedural variables unique to these studies (e.g., use of food restriction, exposure to restraint stress during NOE) interfered with the expression of behavioral effects of smoke, as the positive control (i.e., pure nicotine-treated) groups exhibited significant behavioral effects despite being exposed to these same variables.

Consistent with the current findings, Small et al. (2010) reported that WBE to smoke reduced ICSS response latencies without affecting baseline thresholds. In that study rats were exposed to smoke on at least 20 consecutive days before smoke effects on ICSS were tested. Taken together, these data suggest that WBE to smoke may produce similar effects on baseline ICSS behavior following both initial (current study) and repeated (Small et al. 2010) WBE to smoke.

The lack of smoke effects on most behavioral measures in this study contrasts with previous studies (e.g., Anderson et al., 2004; Small et al., 2010; Suemaru et al., 1992). Numerous procedural differences could account for these findings (e.g. rat strain, housing/feeding conditions), but most of these studies used considerably more intense smoke exposure conditions than those of the current study. Whether such intense exposure conditions (beyond those achieved in cigarette smokers) are required to reliably produce behavioral effects in animals remains an important area for further investigation.

The exposure conditions used in this study produced clinically relevant serum nicotine levels and behaviorally relevant brain nicotine levels, and so provided a reasonable starting point for assessing the behavioral effects of cigarette smoke exposure in rats. A limitation of this study is that it examined only a limited range of NOE and WBE conditions (duration, intensity of exposures). The investigation of a wider range of smoke exposure conditions, as well as additional behavioral models, is needed to validate and interpret these preliminary findings. The narrow dose-response window associated with certain behavioral effects of nicotine (e.g., ICSS threshold reductions, see Fig 7) highlights the need for a systematic evaluation of the behavioral effects of smoke.

Smoke exposure in animals does not fully simulate human cigarette smoking, as it involves passive smoke administration rather than active puffing, relatively short exposure durations, and exposure to potentially aversive stimuli (e.g., odor or irritation from smoke, restraint stress in the case of NOE). Rats also have a higher respiratory rate than humans and are primarily nose-breathers. Any of these factors could compromise the validity of preclinical smoke exposure models, just as differences between smoking and parenteral administration of pure nicotine represent a limitation of these models. While neither smoke exposure nor parenteral dosing models perfectly simulate human cigarette smoking, they represent two complementary approaches that each provide unique information and together may have considerable utility in elucidating key factors involved in tobacco dependence. 
Despite its limitations, the current study established smoke exposure conditions that were clinically relevant and also produced brain nicotine levels similar to those produced by behaviorally active doses of pure nicotine. This study also provided preliminary evidence that the behavioral effects of nicotine delivered via inhalation of tobacco smoke may not be identical to its effects when delivered parenterally. Further study of potential differences between exposures to cigarette smoke and parenteral nicotine may prove useful in understanding and improving animal models of tobacco dependence.

\section{Acknowledgments}

Supported by National Institute on Drug Abuse Grants DA10714 (Pentel PI), T32 DA 07097 (Harris), and F32 DA021935 (Harris), the University of Minnesota Cancer Center Prevention \& Etiology Program (Pentel), the University of Minnesota Transdisciplinary Tobacco Use Research Center Pilot Grant (LeSage and Harris), and the Minneapolis Medical Research Foundation Translational Addiction Research Program (Harris).

\section{References}

Anderson KL, Pinkerton KE, Uyeminami D, Simons CT, Carstens MI, Carstens E. Antinociception induced by chronic exposure of rats to cigarette smoke. Neurosci Lett 2004;366:86-91. [PubMed: 15265596]

Battig K. Differential effects of nicotine and tobacco smoke alkaloids on swimming endurance in the rat. Psychopharmacologia 1970;18:300-304. [PubMed: 5487292]

Bauco P, Wise RA. Potentiation of lateral hypothalamic and midline mesencephalic brain stimulation reinforcement by nicotine: examination of repeated treatment. J Pharmacol Exp Ther 1994;271:294301. [PubMed: 7965727]

Belluzzi JD, Wang R, Leslie FM. Acetaldehyde enhances acquisition of nicotine self-administration in adolescent rats. Neuropsychopharmacology 2005;30:705-712. [PubMed: 15496937]

Benowitz NL. Clinical pharmacology of nicotine: implications for understanding, preventing, and treating tobacco addiction. Clin Pharmacol Ther 2008;83:531-541. [PubMed: 18305452]

Benowitz NL, Kuyt F, Jacob P 3rd. Circadian blood nicotine concentrations during cigarette smoking. Clin Pharmacol Ther 1982;32:758-764. [PubMed: 7140139]

Benowitz NL, Porchet H, Sheiner L, Jacob P 3rd. Nicotine absorption and cardiovascular effects with smokeless tobacco use: comparison with cigarettes and nicotine gum. Clin Pharmacol Ther 1988;44:23-28. [PubMed: 3391001]

Bruijnzeel AW, Prado M, Isaac S. Corticotropin-releasing factor-1 receptor activation mediates nicotine withdrawal-induced deficit in brain reward function and stress-induced relapse. Biol Psychiatry 2009;66:110-117. [PubMed: 19217073]

Brunssen SH, Morgan DL, Parham FM, Harry GJ. Carbon monoxide neurotoxicity: transient inhibition of avoidance response and delayed microglia reaction in the absence of neuronal death. Toxicology 2003;194:51-63. [PubMed: 14636696]

Byrd GD, Robinson JH, Caldwell WS, deBethizy JD. Comparison of measured and FTC-predicted nicotine uptake in smokers. Psychopharmacology (Berl) 1995;122:95-103. [PubMed: 8848540]

Chen BT, Benz JV, Finch GL, Mauderly JL, Sabourin PJ, Yeh HC, Snipes MB. Effect of exposure mode on amounts of radiolabeled cigarette particles in lungs and gastrointestinal tracts of F344 rats. Inhal Toxicol 1995;7:1095-1108.

Clarke PBS, Kumar R. The effects of nicotine on locomotor activity in non-tolerant and tolerant rats. British Journal of Pharmacology 1983a;78:329-337. [PubMed: 6131718]

Clarke PBS, Kumar R. Characterization of the locomotor stimulant action of nicotine in tolerant rats. British Journal of Pharmacology 1983b;80:587-594. [PubMed: 6640208]

Coggins CR. An updated review of inhalation studies with cigarette smoke in laboratory animals. Int $\mathrm{J}$ Toxicol 2007;26:331-338. [PubMed: 17661224]

Counts ME, Hsu FS, Tewes FJ. Development of a commercial cigarette "market map" comparison methodology for evaluating new or non-conventional cigarettes. Regul Toxicol Pharmacol 2006;46:225-242. [PubMed: 16989926] 
Cronenberger C, Mould DR, Roethig HJ, Sarkar M. Population pharmacokinetic analysis of carboxyhaemoglobin concentrations in adult cigarette smokers. Br J Clin Pharmacol 2008;65:30-39. [PubMed: 17764477]

DiFranza JR, Wellman RJ. Sensitization to nicotine: how the animal literature might inform future human research. Nicotine Tob Res 2007;9:9-20. [PubMed: 17365732]

Domino EF. Nicotine induced behavioral locomotor sensitization. Prog Neuropsychopharmacol Biol Psychiatry 2001;25:59-71. [PubMed: 11263759]

Dwoskin LP, Crooks PA, Teng L, Green TA, Bardo MT. Acute and chronic effects of nornicotine on locomotor activity in rats: altered response to nicotine. Psychopharmacology (Berl) 1999;145:442451. [PubMed: 10460322]

Epping-Jordan MP, Watkins SS, Koob GF, Markou A. Dramatic decreases in brain reward function during nicotine withdrawal. Nature 1998;393:76-79. [PubMed: 9590692]

Farkas S, Hussein J, Ariano RE, Sitar DS, Hasan SU. Prenatal cigarette smoke exposure: pregnancy outcome and gestational changes in plasma nicotine concentration, hematocrit, and carboxyhemoglobin in a newly standardized rat model. Toxicol Appl Pharmacol 2006;214:118-125. [PubMed: 16473381]

George O, Ghozland S, Azar MR, Cottone P, Zorrilla EP, Parsons LH, O’ Dell LE, Richardson HN, Koob GF. CRF-CRF1 system activation mediates withdrawal-induced increases in nicotine selfadministration in nicotine-dependent rats. Proc Natl Acad Sci U S A 2007;104:17198-17203. [PubMed: 17921249]

Ghosheh O, Dwoskin LP, Li WK, Crooks PA. Residence times and half-lives of nicotine metabolites in rat brain after acute peripheral administration of [2'-(14)C]nicotine. Drug Metab Dispos 1999;27:1448-1455. [PubMed: 10570026]

Gomita Y, Furuno K, Eto K, Okazaki M, Suemaru K, Araki Y. Effect of cigarette smoking on theophylline pharmacokinetics in rats. J Pharm Pharmacol 1991a;43:621-624. [PubMed: 1685519]

Gomita Y, Suemaru K, Furuno K, Araki Y. Tail-tremor induced by exposure to cigarette smoke in rats. Pharmacol Biochem Behav 1991b;40:453-455. [PubMed: 1805247]

Guillem K, Vouillac C, Azar MR, Parsons LH, Koob GF, Cador M, Stinus L. Monoamine oxidase inhibition dramatically increases the motivation to self-administer nicotine in rats. J Neurosci 2005;25:8593-8600. [PubMed: 16177026]

Harris AC, Atkinson DM, Aase DM, Gewirtz JC. Double dissociation in the neural substrates of acute opiate dependence as measured by withdrawal-potentiated startle. Neuroscience 2006;139:12011210. [PubMed: 16600512]

Harrison AA, Gasparini F, Markou A. Nicotine potentiation of brain stimulation reward reversed by DH beta E and SCH 23390, but not by eticlopride, LY 314582 or MPEP in rats. Psychopharmacology (Berl) 2002;160:56-66. [PubMed: 11862374]

Hecht SS. Carcinogenicity studies of inhaled cigarette smoke in laboratory animals: old and new. Carcinogenesis 2005;26:1488-1492. [PubMed: 15930027]

Henningfield JE, Keenan RM. Nicotine delivery kinetics and abuse liability. J Consult Clin Psychol 1993;61:743-750. [PubMed: 8245272]

Henningfield JE, Stapleton JM, Benowitz NL, Grayson RF, London ED. Higher levels of nicotine in arterial than in venous blood after cigarette smoking. Drug Alc Depend 1993;33:23-29.

Herning RI, Jones RT, Benowitz NL, Mines AH. How a cigarette is smoked determines blood nicotine levels. Clin Pharmacol Ther 1983;33:84-90. [PubMed: 6848303]

Hieda Y, Keyler DE, VanDeVoort JT, Niedbala RS, Raphael DE, Ross CA, Pentel PR. Immunization of rats reduces nicotine distribution to brain. Psychopharmacology (Berl) 1999;143:150-157. [PubMed: 10326777]

Hrubes V, Battig K. Effect of inhaled cigarette smoke on swimming endurace in the rat. Arch Environ Health 1970;21:20-24. [PubMed: 5422320]

Hurt RD, Dale LC, Offord KP. Serum nicotine and cotinine levels during nicotine patch therapy. Clinical Pharmacology and Therapeutics 1993;54:98-106. [PubMed: 8330471]

Huston-Lyons D, Kornetsky C. Effects of nicotine on the threshold for rewarding brain stimulation in rats. Pharmacol Biochem Behav 1992;41:755-759. [PubMed: 1594644] 
Jacob P 3rd, Wilson M, Benowitz NL. Improved gas chromatographic method for the determination of nicotine and cotinine in biologic fluids. J Chromatogr 1981;222:61-70. [PubMed: 6783675]

Kornetsky C, Esposito RU. Euphorigenic drugs: effects on the reward pathways of the brain. Fed Proc 1979;38:2473-2476. [PubMed: 488370]

Lerman C, LeSage MG, Perkins KA, O’Malley SS, Siegel SJ, Benowitz NL, Corrigall WA. Translational research in medication development for nicotine dependence. Nat Rev Drug Discov 2007;6:746762. [PubMed: 17690709]

LeSage MG, Keyler DE, Shoeman D, Raphael D, Collins G, Pentel PR. Continuous nicotine infusion reduces nicotine self-administration in rats with 23-h/day access to nicotine. Pharmacol Biochem Behav 2002;72:279-289. [PubMed: 11900798]

Malin DH, Lake JR, Lin A, Saldana M, Balch L, Irvin ML, Chandrasekara H, Alvarado CL, Hieda Y, Keyler DE, Pentel PR, Ennifar S, Basham LE, Naso R, Fattom A. Passive immunization against nicotine prevents nicotine alleviation of nicotine abstinence syndrome. Pharmacol Biochem Behav 2001;68:87-92. [PubMed: 11274712]

Malin DH, Lake JR, Newlin-Maultsby P, Roberts LK, Lanier JG, Carter VA, Cunningham JS, Wilson OB. Rodent model of nicotine abstinence syndrome. Pharmacol Biochem Behav 1992;43:779-784. [PubMed: 1448472]

Malin DH, Lake JR, Payne MC, Short PE, Carter VA, Cunningham JS, Wilson OB. Nicotine alleviation of nicotine abstinence syndrome is naloxone-reversible. Pharmacol Biochem Behav 1996;53:81-85. [PubMed: 8848464]

Markou A, Koob GF. Construct validity of a self-stimulation threshold paradigm: effects of reward and performance manipulations. Physiol Behav 1992;51:111-119. [PubMed: 1741436]

Mathieu-Kia AM, Kellogg SH, Butelman ER, Kreek MJ. Nicotine addiction: insights from recent animal studies. Psychopharmacology (Berl) 2002;162:102-118. [PubMed: 12110988]

Miller DK, Harrod SB, Green TA, Wong MY, Bardo MT, Dwoskin LP. Lobeline attenuates locomotor stimulation induced by repeated nicotine administration in rats. Pharmacol Biochem Behav 2003;74:279-286. [PubMed: 12479946]

Miyagawa M, Honma T, Sato M, Hasegawa H. Acute effects of inhalation exposure to carbon monoxide on schedule-controlled operant behavior and blood carboxyhemoglobin levels in rats. Ind Health 1995;33:119-129. [PubMed: 8543475]

Mousa SA, Aloyo VJ, Van Loon GR. Tolerance to tobacco smoke- and nicotine-induced analgesia in rats. Pharmacol Biochem Behav 1988;31:265-268. [PubMed: 3244703]

Nowakowska E, Kus K, Florek E, Czubak A, Jodynis-Liebert J. The influence of tobacco smoke and nicotine on antidepressant and memory-improving effects of venlafaxine. Hum Exp Toxicol 2006;25:199-209. [PubMed: 16696296]

O'Dell LE, Khroyan TV. Rodent models of nicotine reward: what do they tell us about tobacco abuse in humans? Pharmacol Biochem Behav 2009;91:481-488. [PubMed: 19121334]

Pratt JA, Stolerman IP, Garcha HS, Giardini V, Feyerabend C. Discriminative stimulus properties of nicotine: further evidence for mediation at a cholinergic receptor. Psychopharmacology (Berl) 1983;81:54-60. [PubMed: 6415731]

Robinson TE, Berridge KC. The neural basis of drug craving: an incentive-sensitization theory of addiction. Brain Res Brain Res Rev 1993;18:247-291. [PubMed: 8401595]

Roiko SA, Harris AC, Lesage MG, Keyler DE, Pentel PR. Passive immunization with a nicotine-specific monoclonal antibody decreases brain nicotine levels but does not precipitate withdrawal in nicotinedependent rats. Pharmacol Biochem Behav 2009;93:105-111. [PubMed: 19393688]

Rose JE. Nicotine and nonnicotine factors in cigarette addiction. Psychopharmacology (Berl) 2006;184:274-285. [PubMed: 16362402]

Rose JE, Behm FM, Levin ED. Role of nicotine dose and sensory cues in the regulation of smoke intake. Pharmacol Biochem Behav 1993;44:891-900. [PubMed: 8469698]

Rose JE, Behm FM, Westman EC, Coleman RE. Arterial nicotine kinetics during cigarette smoking and intravenous nicotine administration: implications for addiction. Drug Alcohol Depend 1999;56:99_ 107. [PubMed: 10482401]

Rotenberg KS, Adir J. Pharmacokinetics of nicotine in rats after multiple-cigarette smoke exposure. Toxicol Appl Pharmacol 1983;69:1-11. [PubMed: 6857681] 
Rotenberg KS, Miller RP, Adir J. Pharmacokinetics of nicotine in rats after single-cigarette smoke inhalation. J Pharm Sci 1980;69:1087-1090. [PubMed: 7411415]

Rothwell PE, Thomas MJ, Gewirtz JC. Distinct profiles of anxiety and dysphoria during spontaneous withdrawal from acute morphine exposure. Neuropsychopharmacology 2009;34:2285-2295. [PubMed: 19494807]

Rowan JD, Fountain SB. Carbon monoxide exposure reduces the rewarding quality of brain-stimulation reward in rats. Neurotoxicol Teratol 1991;13:175-179. [PubMed: 2046637]

Russell MA, Jarvis M, Iyer R, Feyerabend C. Relation of nicotine yield of cigarettes to blood nicotine concentrations in smokers. Br Med J 1980;280:972-976. [PubMed: 7417765]

Sahley TL, Berntson GG. Antinociceptive effects of central and systemic administrations of nicotine in the rat. Psychopharmacology (Berl) 1979;65:279-283. [PubMed: 117500]

Samaha AN, Yau WY, Yang P, Robinson TE. Rapid delivery of nicotine promotes behavioral sensitization and alters its neurobiological impact. Biol Psychiatry 2005;57:351-360. [PubMed: 15705350]

Simons CT, Cuellar JM, Moore JA, Pinkerton KE, Uyeminami D, Carstens MI, Carstens E. Nicotinic receptor involvement in antinociception induced by exposure to cigarette smoke. Neurosci Lett 2005;389:71-76. [PubMed: 16095820]

Skjei KL, Markou A. Effects of repeated withdrawal episodes, nicotine dose, and duration of nicotine exposure on the severity and duration of nicotine withdrawal in rats. Psychopharmacology (Berl) 2003;168:280-292. [PubMed: 12712232]

Small E, Shah HP, Davenport JJ, Geier JE, Yavarovich KR, Yamada H, Sabarinath SN, Derendorf H, Pauly JR, Gold MS, Bruijnzeel AW. Tobacco smoke exposure induces nicotine dependence in rats. Psychopharmacology (Berl) 2010;208:143-158. [PubMed: 19936715]

Suemaru K, Oishi R, Gomita Y, Saeki K, Araki Y. Effect of long-term cigarette smoke exposure on locomotor activity and brain monoamine levels in rats. Pharmacol Biochem Behav 1992;41:655658. [PubMed: 1584847]

U.S. Department of Health and Human Services. Nicotine addiction: Health consequences of smoking. Washington: DHHS; 1999.

Vezina P, McGehee DS, Green WN. Exposure to nicotine and sensitization of nicotine-induced behaviors. Prog Neuropsychopharmacol Biol Psychiatry 2007;31:1625-1638. [PubMed: 17936462]

Wakasa Y, Takada K, Yanagita T. Reinforcing effect as a function of infusion speed in intravenous selfadministration of nicotine in rhesus monkeys. Nihon Shinkei Seishin Yakurigaku Zasshi 1995;15:5359. [PubMed: 7750017]

Watkins SS, Stinus L, Koob GF, Markou A. Reward and somatic changes during precipitated nicotine withdrawal in rats: centrally and peripherally mediated effects. J Pharmacol Exp Ther 2000;292:1053-1064. [PubMed: 10688623]

Winders SE, Grunberg NE, Benowitz NL, Alvares AP. Effects of stress on circulating nicotine and cotinine levels and in vitro nicotine metabolism in the rat. Psychopharmacology (Berl) 1998;137:383-390. [PubMed: 9676899] 
Phase 1

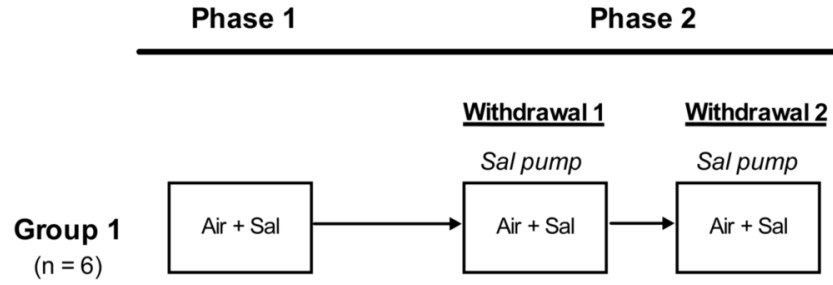

Phase 3
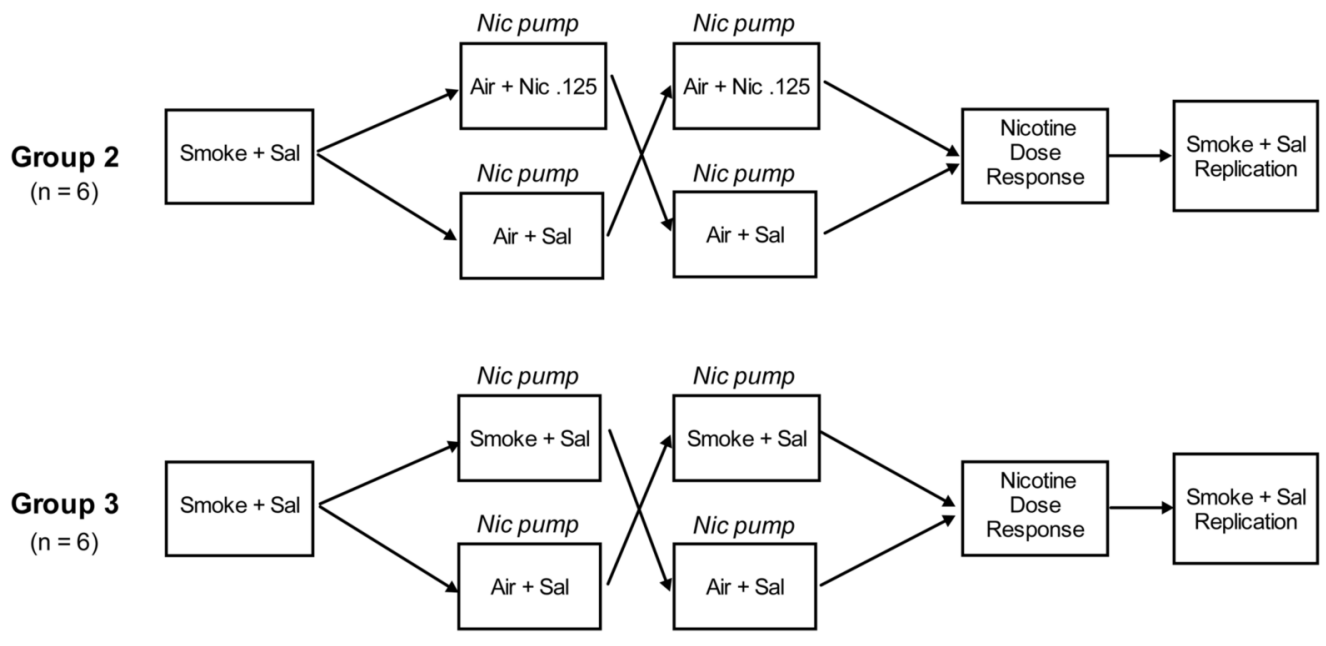

Figure 1.

Timeline for experimental procedures in Experiment 3. Habituation days are not portrayed for any Phase. Nic Pump, Sal Pump = Testing occurred $23 \mathrm{hr}$ following cessation of a 7-day continuous infusion of nicotine $(3.2 \mathrm{mg} / \mathrm{kg} / \mathrm{day})$ or saline. Nicotine dose-response $=$ testing occurred following $4 \mathrm{hr}$ exposure to Air + Sal or Air + Nicotine $(0.125,0.25$, or $0.5 \mathrm{mg} / \mathrm{kg}$, s.c.). See text for definition of other abbreviations and further details. 


\section{Nose-only Exposure}
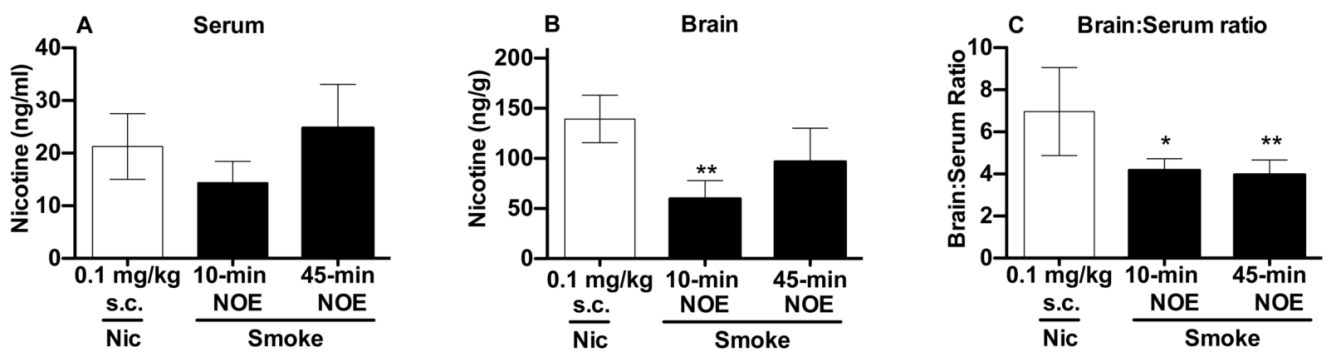

\section{Whole-body Exposure}
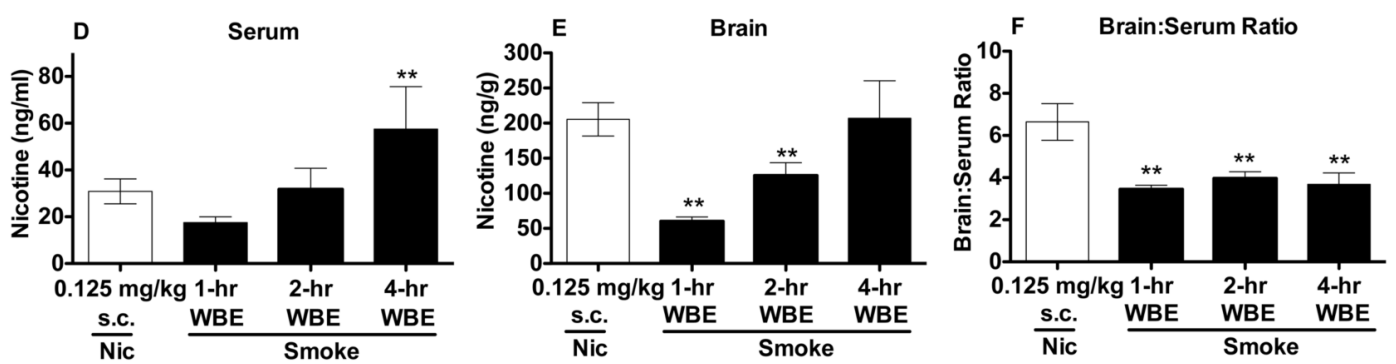

Figure 2.

Serum (A) and brain (B) nicotine levels and brain:serum nicotine concentration ratios (C) (Mean \pm SD) following s.c. injection of nicotine $0.1 \mathrm{mg} / \mathrm{kg}$ or $10-$ or $45-\mathrm{min}$ NOE to smoke. ${ }^{*}{ }^{* *}$ Significantly different from s.c. nicotine $0.1 \mathrm{mg} / \mathrm{kg}, \mathrm{p}<0.05,0.01$. Serum (D) and brain (E) nicotine levels and brain:serum nicotine concentration ratios (F) (Mean \pm SD) following s.c. injection of nicotine $0.125 \mathrm{mg} / \mathrm{kg}$ or $1-, 2-$, or $4-\mathrm{hr}$ WBE to smoke. * Significantly different from s.c. nicotine $0.125 \mathrm{mg} / \mathrm{kg}, \mathrm{p}<0.01$. 

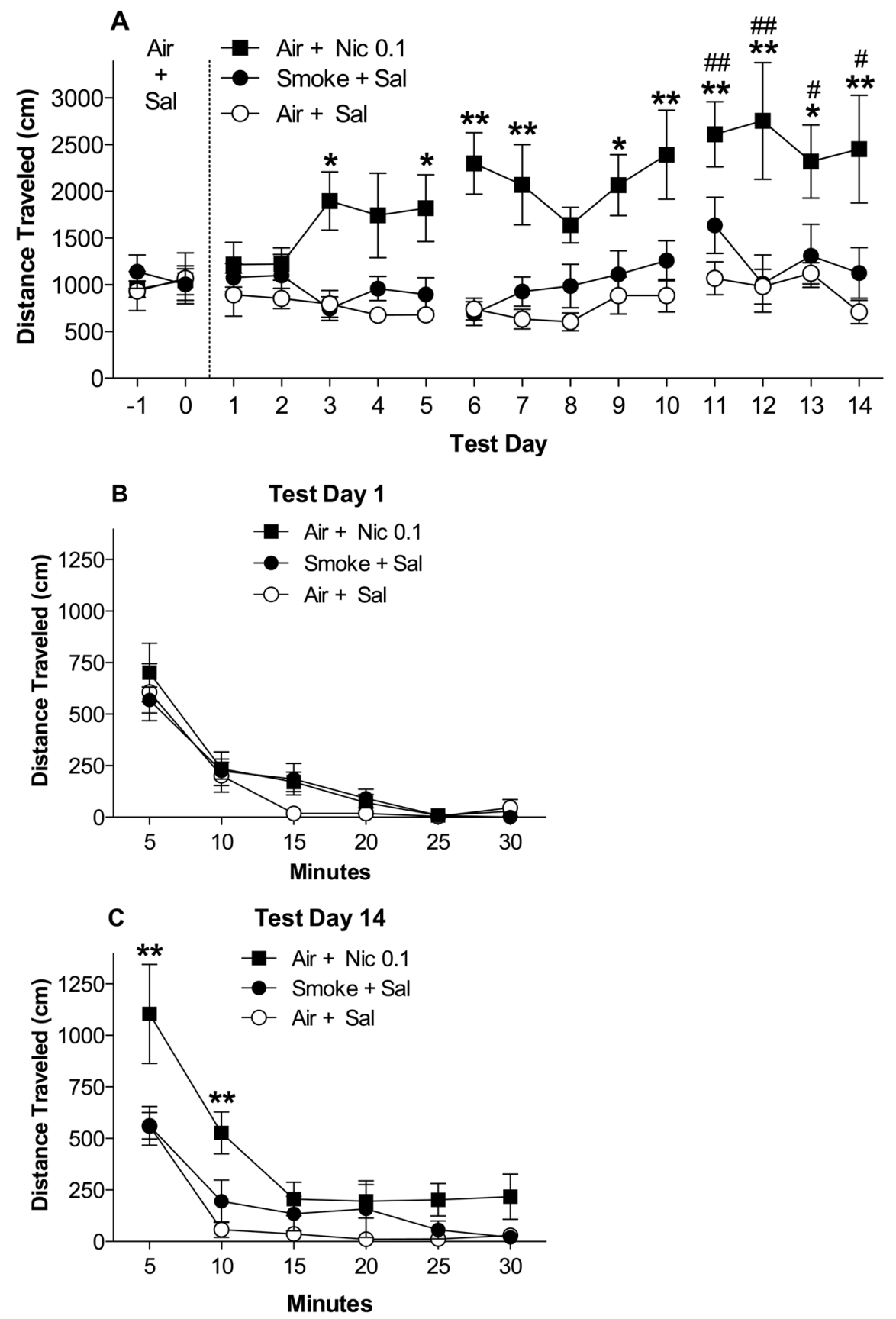

Figure 3.

(A) Total distance traveled (Mean \pm SEM) during each 30 min post-exposure test during Habituation and Sensitization (see text). ${ }^{*}, * *$ Significantly different from the Air + Sal group (negative control) on that test day, $\mathrm{p}<0.05,0.01 . \#$, \#\# Significantly different from test day 1 for that group, $\mathrm{p}<0.05,0.01$. Total distance traveled (Mean \pm SEM) during each 5-min block on the first (B) and final (C) day of Sensitization (test days 1 and 14). ${ }^{* *}$ Significantly different from Air + Sal group at that 5-min block, $\mathrm{p}<0.01$. 


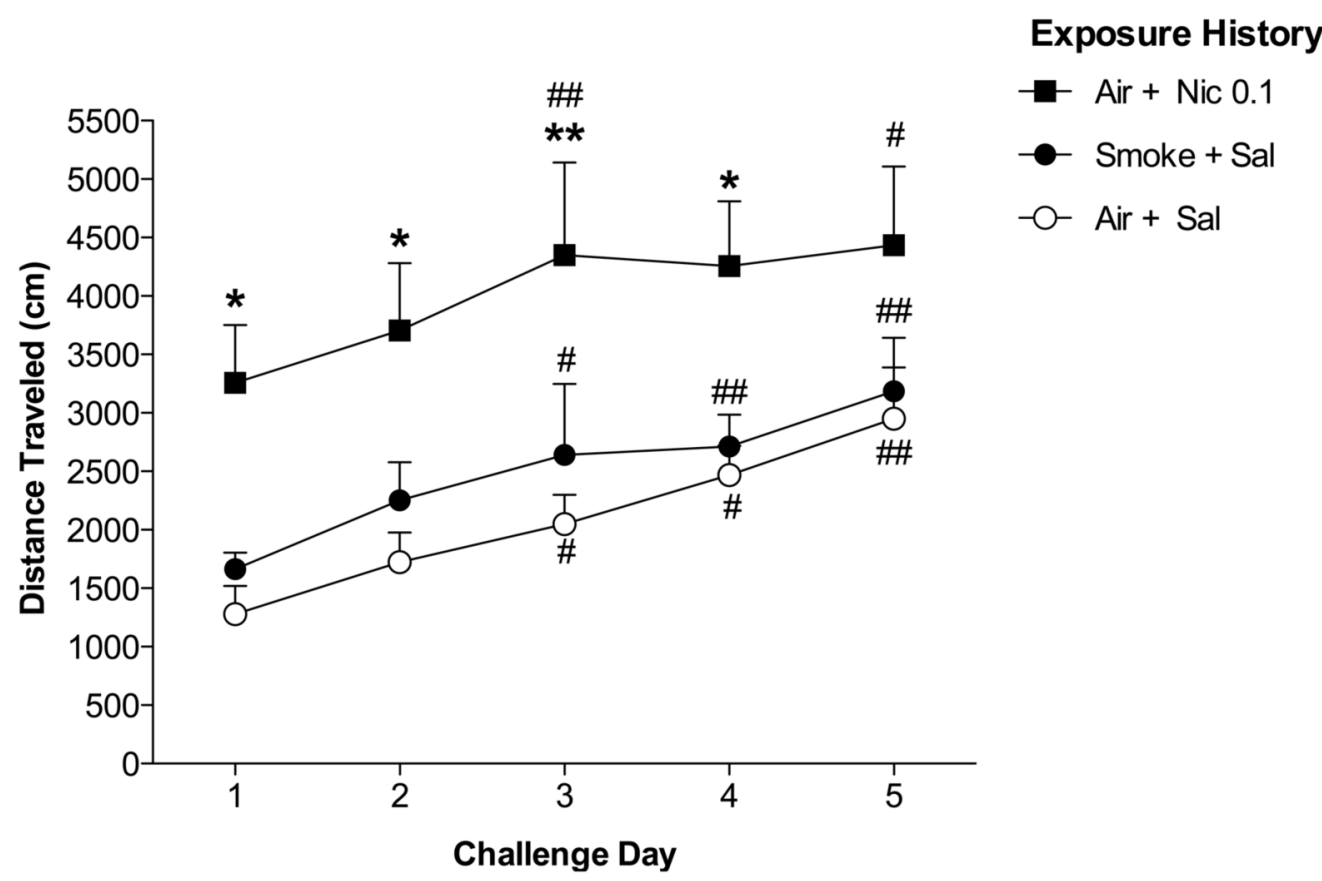

Figure 4.

Total distance traveled (Mean + SEM) during each 30 min post-exposure test during the Nicotine Challenge phase. All rats were injected with nicotine $(0.3 \mathrm{mg} / \mathrm{kg}$, s.c.) prior to the post-exposure test on each challenge day. Group designations refer to treatment during the Sensitization phase. ${ }^{*, * *}$ Significantly different from Air + Sal pre-exposed group on that challenge day, $\mathrm{p}<0.05,0.01$. \#, \#\# Significantly different from challenge day $1, \mathrm{p}<0.05,0.01$. 
A

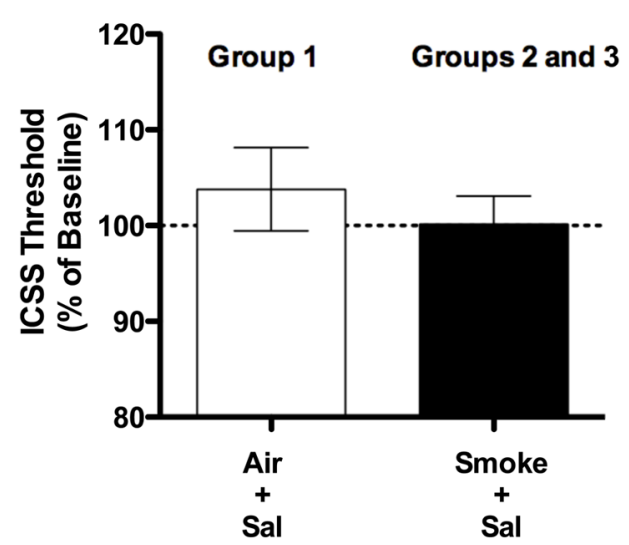

B

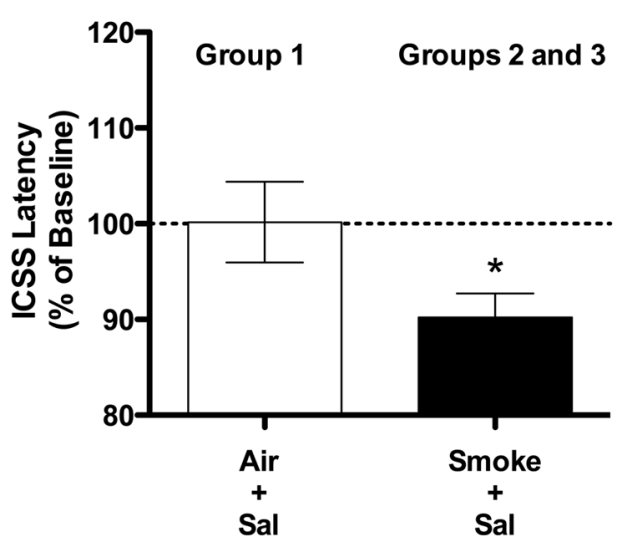

Figure 5.

ICSS thresholds (A) and response latencies (B) on the test day during Phase 1 of Experiment 3 (expressed as percent of baseline, mean \pm SEM) following exposure to Air + Sal (Group 1) or Smoke + Sal (Groups 2 and 3, averaged across both groups). ${ }^{*}$ p $<0.05$ compared to Air + Sal exposure in Group 1. 


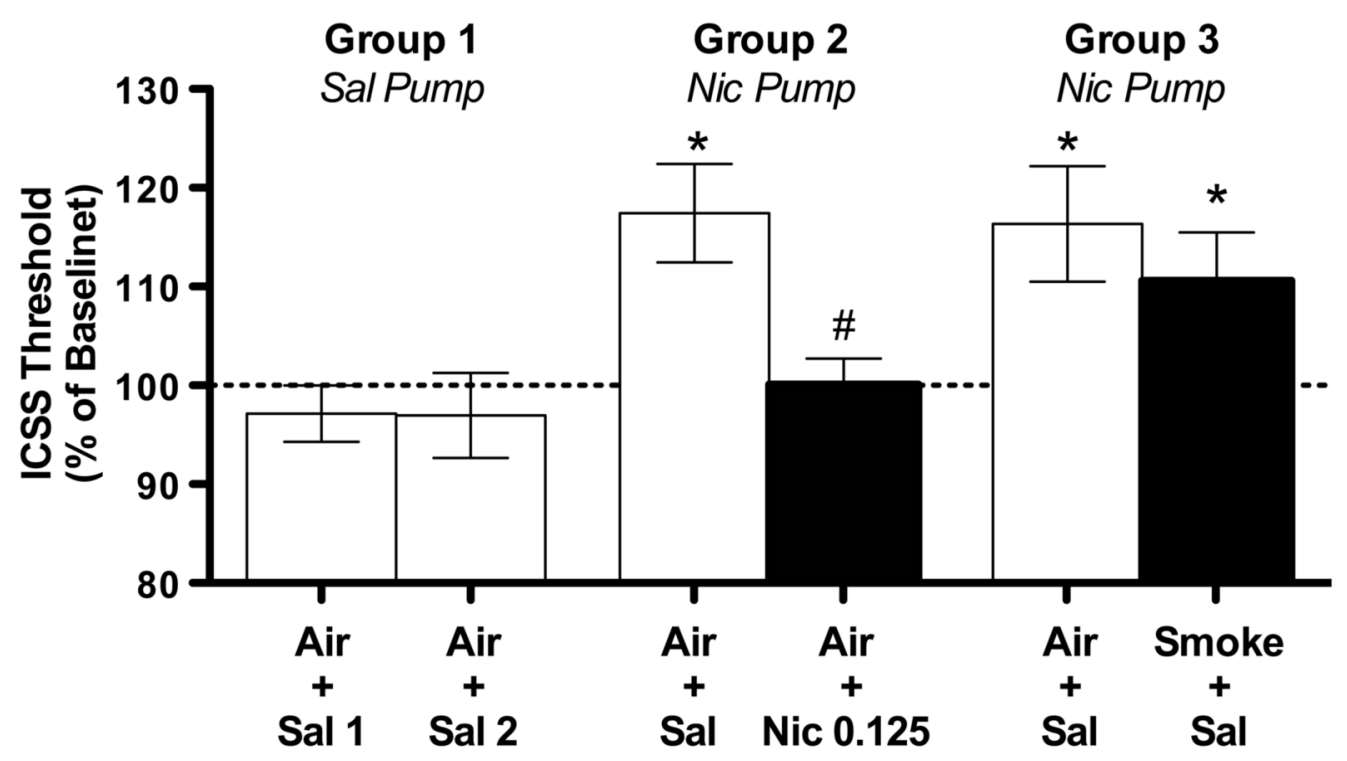

Figure 6.

ICSS thresholds on the withdrawal day during Phase 2 of Experiment 3 (expressed as percent of baseline, mean \pm SEM) in each group following different WBE and s.c. injection conditions. Air + Sal 1, Air + Sal 2 = first and second saline pump/ Air + Sal exposures for Group 1 (negative control). See text for definition of other abbreviations and further details. ${ }^{*} \mathrm{p}<0.05$ compared to Group 1 (data for Group 1 collapsed across both Air + Sal 1 and Air + Sal 2). \# $\mathrm{p}<0.05$ compared to Air + Sal (i.e., spontaneous withdrawal condition) in that group. 


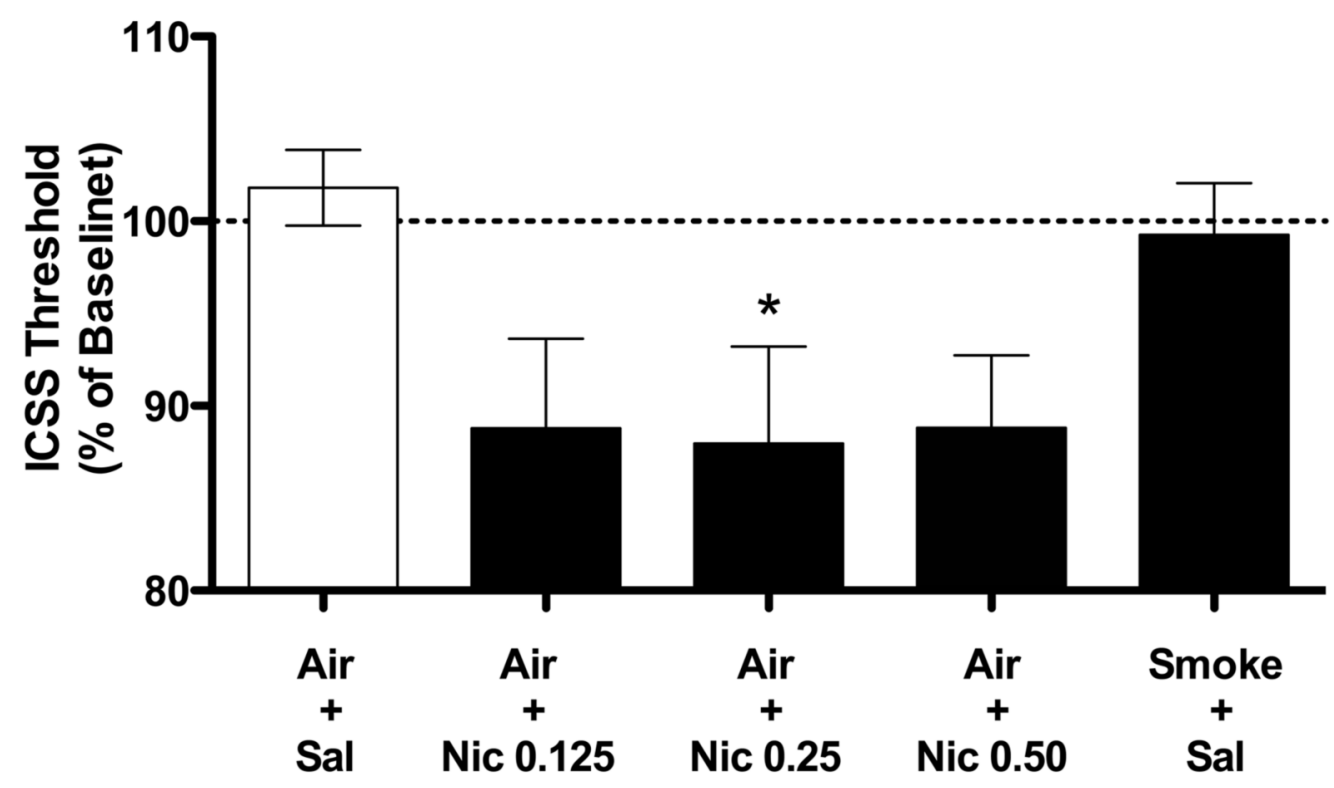

Figure 7.

ICSS thresholds (expressed as percent of baseline, mean \pm SEM) following s.c. nicotine or 4hr WBE to cigarette smoke under baseline (non-withdrawal) conditions during Phase 3 of Experiment 3. ${ }^{*} \mathrm{p}<0.05$ compared to Air + Sal exposure. 


\section{Table 1}

Mean baseline thresholds (in $\mu \mathrm{A}$ ) and response latencies (in sec) for experimental groups during Phases 1 and 2 of Experiment 3. Baseline data during Phase 2 are averaged across both osmotic minipump exposures for each group.

\begin{tabular}{c|c|c|c|c}
\hline & \multicolumn{2}{|c|}{ Phase 1 } & \multicolumn{2}{c}{ Phase 2 } \\
\cline { 2 - 5 } & Threshold $(\boldsymbol{\mu A})$ & Latency (sec) & Threshold ( $\boldsymbol{\mu A})$ & Latency (sec) \\
\hline Iroup 1 & $79.4 \pm 13.7$ & $2.3 \pm 0.2$ & $88.3 \pm 15.1$ & $2.3 \pm 0.1$ \\
Group 2 & $76.5 \pm 3.7$ & $2.5 \pm 0.2$ & $75.6 \pm 3.1$ & $2.4 \pm 0.1$ \\
Group 3 & $82.3 \pm 10.8$ & $2.9 \pm 0.2$ & $72.4 \pm 5.0$ & $2.6 \pm 0.2$ \\
\hline
\end{tabular}

